\title{
Diploid Male Gametes Circumvent Hybrid Sterility Between Asian and African Rice Species
}

OPEN ACCESS

Edited by:

Prem Bhalla,

The University of Melbourne, Australia

Reviewed by:

Sushma Naithani,

Oregon State University,

United States

Takashi Okada,

University of Adelaide, Australia Mary Catherine Christey,

The New Zealand Institute for Plant and Food Research Ltd.,

New Zealand

*Correspondence:

Yuji Kishima

kishima@abs.agr.hokudai.ac.jp

Specialty section: This article was submitted to Plant Breeding,

a section of the journal

Frontiers in Plant Science

Received: 02 July 2020 Accepted: 29 September 2020

Published: 05 November 2020

Citation:

Kuniyoshi D, Masuda I, Kanaoka Y, Shimazaki-Kishi Y, Okamoto $Y$, Yasui $H$, Yamamoto $T$,

Nagaki $K$, Hoshino Y, Koide $Y$,

Takamure I and Kishima Y (2020)

Diploid Male Gametes Circumvent

Hybrid Sterility Between Asian

and African Rice Species.

Front. Plant Sci. 11:579305.

doi: 10.3389/fp/s.2020.579305
Daichi Kuniyoshi', Itaru Masuda1, Yoshitaka Kanaoka1, Yuki Shimazaki-Kishi', Yoshihiro Okamoto ${ }^{2}$, Hideshi Yasui ${ }^{3}$, Toshio Yamamoto ${ }^{4}$, Kiyotaka Nagaki ${ }^{4}$, Yoichiro Hoshino $^{5}$, Yohei Koide ${ }^{1}$, Itsuro Takamure ${ }^{1}$ and Yuji Kishima ${ }^{1 *}$

${ }^{1}$ Laboratory of Plant Breeding, Research Faculty of Agriculture, Hokkaido University, Sapporo, Japan, ${ }^{2}$ Laboratory of Plant Breeding, Rakuno Gakuen University, Ebetsu, Japan, ${ }^{3}$ Plant Breeding Laboratory, Faculty of Agriculture, Kyushu University, Fukuoka, Japan, ${ }^{4}$ Institute of Plant Science and Resources, Okayama University, Kurashiki, Japan, ${ }^{5}$ Field Science Center for Northern Biosphere, Hokkaido University, Sapporo, Japan

In $F_{1}$ hybrids of Oryza sativa (Asian rice) and Oryza glaberrima (African rice), heterozygosity leads to a complete gamete abortion because of allelic conflict at each of the 13 hybrid sterility (HS) loci. We systematically produced 19 plants from the $F_{1}$ hybrids of both the rice species by the anther culture (AC) method. Five of the 19 interspecific hybrid plants were partially fertile and able to produce seeds. Unlike ordinal doubled haploid plants resulting from AC, these regenerated plants showed various ploidy levels (diploid to pentaploid) and different zygosities (completely homozygous, completely heterozygous, and a combination). These properties were attributable to meiotic anomalies in the interspecific hybrid $F_{1}$ plants. Examination of the genetic structures of the regenerated plants suggested meiotic non-reduction took place in the interspecific hybrid $F_{1}$ plants. The centromeric regions in the regenerated plants revealed that the abnormal first and/or second divisions of meiosis, namely the first division restitution (FDR) and/or second division restitution (SDR), had occurred in the interspecific hybrid. Immunohistochemical observations also verified these phenomena. FDR and SDR occurrences at meiosis might strongly lead to the formation of diploid microspores. The results demonstrated that meiotic anomalies functioned as a reproductive barrier occurred before the HS genes acted in gamete of the interspecific hybrid. Although such meiotic anomalies are detrimental to pollen development, the early rescue of microspores carrying the diploid gamete resulted in the fertile regenerated plants. The five partially fertile plants carrying tetraploid genomes with heterozygous alleles of the HS loci produced fertile diploid pollens, implying that the diploid gametes circumvented the allelic conflicts at the HS loci. We also proposed how diploid male gametes avoid HS with the killer-protector model.

Keywords: anther culture, division restitution, hybrid sterility, interspecific hybrid, meiosis, rice, tetraploid, diploid gamete 


\section{INTRODUCTION}

Although cultivated rice species Oryza sativa (Asian rice) and Oryza glaberrima (African rice) both have AA genomes, the first filial generation $\left(F_{1}\right)$ between these two species does not produce fertile seeds (Morinaga and Kuriyama, 1957; Oka, 1957). This type of reproductive isolation, designated as hybrid sterility (HS), is associated with abnormal gamete development and sterility (Morinaga and Kuriyama, 1957; Oka, 1957; Sano et al., 1979). To date, 13 HS loci have been reported to be involved in HS in $\mathrm{F}_{1}$ hybrids between $O$. sativa and O. glaberrima (sat-gla) (Sano, 1983, 1990; Doi et al., 1998, 1999; Taguchi et al., 1999; Ren et al., 2006; Zhang et al., 2006; Li et al., 2011; Ouyang and Zhang, 2013; Xu et al., 2014; Yu et al., 2018). In particular, pollen sterility is noticeable in these hybrids, and fertility is completely lost; in contrast, female gametes do not exhibit such severe sterility, as seeds are produced when fertile pollen grains are crossed (Jones et al., 1997; Garavito et al., 2010). Microspores in the process of completing meiosis and developing into pollen are capable of differentiating into plants. If pollen destined for abortion can be rescued during early developmental stages, it could create hybrid plants. Not only are these individuals useful as genetic resources, but they also have a high potential in elucidating the mechanism of hybrid sterility.

In the 1960s, Gopalakrishnan et al. (1964) and Oka (1968) created individuals producing fertile seeds in $\mathrm{F}_{1}$ tetraploid hybrids of sat-gla. In 1980, Woo and Huang reported that anther culture (AC) of an $\mathrm{F}_{1}$ hybrid of sat-gla gave rise to tetraploid, diploid, and haploid plants (Woo et al., 1978). Unfortunately, these significant findings were given scant attention, being published too early to be of wide interest. The results described in those studies have thus not been validated, and the fertility of such $F_{1}$ tetraploid hybrids has not been analyzed in detail. Furthermore, the mechanism responsible for the formation of polyploids following $\mathrm{AC}$ of the interspecific hybrids has not been studied subsequently. In these interspecific hybrids, detailed observations are required to determine if pairing between genomes occurs during meiosis and whether distributions of homologous chromosomes in the first meiotic division and/or sister chromatids in the second meiotic division take place.

In general, $\mathrm{AC}$ can duplicate haploid genomes derived from male gametes to form a doubled haploid (DH) individual with complete homozygosity (Guha and Maheshwari, 1964; Niizeki and Oono, 1968; Germana, 2011). The differentiated individual from AC is, therefore, a complete pure line (Yan et al., 2017). In the present study, 19 plants were differentiated from the calli induced from anther-containing microspores of an $\mathrm{F}_{1}$ hybrid of sat-gla. These differentiated individuals were mostly polyploids and exhibited heterozygosity in many genomic regions, which might cause allelic conflicts of HS loci. Nonetheless, some tetraploid individuals produced fertile seeds and the offspring in the next generation. Many studies on HS between sat-gla have mainly focused on $H S$ genes, but little attention has been paid to other genetic factors. These polyploids were mainly a consequence of meiotic anomalies attributable to a failure during first or second meiotic divisions, namely the first division restitution (FDR) and second division restitution (SDR). The diploid gametes of the fertile tetraploids could circumvent the allelic conflicts at heterozygous $H S$ loci that cause hybrid sterility. Anomalous meiosis in the $\mathrm{F}_{1}$ hybrid that preceded the action of the HS genes should be added as one of the causes of hybrid sterility. Here, we demonstrate that diploid gametes can circumvent HS between sat-gla and thus allow partially fertile individuals to be regenerated. We also examine the relationship between meiotic anomalies and HS and discuss the defeat of HS by polyploidization.

\section{MATERIALS AND METHODS}

\section{Plant Materials and AC}

The calli derived from AC in this study originated from the same materials obtained by Kanaoka et al. (2018). Interspecific $\mathrm{F}_{1}$ hybrid individuals were produced by crossing O. glaberrima Steud. with $O$. sativa L. ssp. japonica. The seed parent O. glaberrima accession IRGC 104038 from Senegal (designated as WK21) was kindly provided by the International Rice Germplasm Center of the International Rice Research Institute (Philippines) and conserved at Kyushu University. Nipponbare (Nip) was used as the pollen parent. Callus induction from AC was carried out according to Kanaoka et al. (2018) and is described as follows. After sterilization with $70 \%$ ethanol, panicles with spikelets at the booting stage (uninucleate stage) were incubated at $10^{\circ} \mathrm{C}$ (low temperature treatment) in the dark for 4-10 days. Approximately 70 anthers per dish were plated onto RI-13 callus-induction medium (Woo et al., 1978) prepared in a $ø 90 \mathrm{~mm} \times \mathrm{H} 15 \mathrm{~mm}$ plastic dish. The plated anthers were then cultured at $25^{\circ} \mathrm{C}$ in the dark for 4 months. Grown calli were transplanted to fresh medium to promote further growth. To induce plant regeneration, calli grown to a diameter of $2 \mathrm{~mm}$ were moved to N6 medium (Chu, 1978) and incubated under light conditions at $25^{\circ} \mathrm{C}$. When plantlets developed and roots emerged in the medium, the plantlets were transplanted to sterile soil, which included equal amounts of peat moss, vermiculite, and compost. The rice plants were grown under shade conditions in the greenhouse. Phenotypic traits in terms of pollen fertility, seed set rate, seed length, seed width, plant height, leaf length, leaf breadth, ligule length, and pistil color, were measured with four, six, and five individuals from the self-pollinated progenies of three fertile tetraploid lines, RP2-25 (from \#25), RP2-38 (from \#38), and RP2-80 (from \#80), respectively. For counting precise seed numbers, the panicles of these materials were sacked to capture shattering seeds after heading.

\section{Pollen Observation}

The anthers for pollen observation were collected based on a distance between the auricles of flag leaf and penultimate leaf. To estimate microspore stages, microspore was collected when then the two auricles were separated by the following distances: -1.0 to $+1.0 \mathrm{~cm}$ for the uninucleate stage and +2.0 to $+6.0 \mathrm{~cm}$ for the binucleate state. In addition, mature pollen was collected after heading. These distances were almost all the same among the plant materials used. Collected anthers were fixed with formalin-acetic acid-alcohol fixative and then 
prepared for microscopic observation. For observation at each microspore developmental stage, anthers were squashed on a microscope slide. After addition of $10 \mu \mathrm{l}$ acetocarmine (Wako 1st grade, Fujifilm Wako Pure Chemical Corporation, Osaka, Japan) or Lugol's iodine staining solution $\left[0.15 \%(\mathrm{w} / \mathrm{v}) \mathrm{I}_{2}, 1.5 \%\right.$ $(\mathrm{w} / \mathrm{v}) \mathrm{KI}$, the slide was covered with a cover slip and observed to respectively determine the pollen developmental stage or fertility of mature pollen.

\section{Chromosome Counting}

For chromosome number estimation, mitosis was observed using cells from root tips of regenerated plant \#20, which were pretreated using $2 \mathrm{mM}$ 8-hydroxyquinoline for $2-2.5 \mathrm{~h}$ at $20^{\circ} \mathrm{C}$. After fixation, $1 \mathrm{~mm}$ of each root tip was cut off and macerated in enzyme solution consisting of $6.0 \%(\mathrm{w} / \mathrm{v})$ Cellulase Onozuka RS (Yakult Pharmaceutical, Tokyo, Japan), 6.0\% (w/v) Pectolyase Y-23 (Kyowa Chemical Products, Kagawa, Japan), and $75 \mathrm{mM}$ $\mathrm{KCl}$ for $60 \mathrm{~min}$ at $37^{\circ} \mathrm{C}$. The root tips were washed with a drop of distilled water for $5 \mathrm{~min}$ on a glass slide. To spread cells, each root tip was thoroughly squashed using a needle with $10 \mu \mathrm{l}$ ethanol-acetic acid [3:1 (v/v)], and the slide was then flame-dried. The spread cells were stained for 30 min with Giemsa solution (Kanto Chemical Co., INC., Tokyo, Japan) diluted 30 times with Sorensen's phosphate buffer ( $\mathrm{pH}$ 6.8). After washing with distilled water, the number of chromosomes was counted under an optical microscope (Olympus BX-50 F, Olympus, Tokyo, Japan).

\section{Ploidy Analysis}

Ploidy levels of materials were examined by measuring relative nuclear DNA amounts by flow cytometry as described in Miyashita et al. (2011). Nuclear suspensions obtained by extraction of small pieces of leaf tissue with nuclear extraction buffer (Quantum Stain NA 2A, CytoTechs, Ibaraki, Japan) were filtered through a $30-\mu \mathrm{m}$ nylon mesh (Partec Celltrics, Lincolnshire, IL, United States). The fluorescent intensity of nuclei stained with DAPI ( $\mathrm{pH}$ 7.5) was measured using a flow cytometer (Partec PA, Partec GmbH, Münster, Germany). The ploidy level of each examined individual was estimated using the fluorescent intensity of diploid tissue as a standard.

\section{Genotyping}

PCR detection of polymorphisms between WK21 and Nip was based on comparison of their complete genome sequences. The complete genome sequence of Nip was obtained from IRGSP1.0 (RAP-DB), while that of WK21 was sequenced and deposited into the DDBJ under accession number DRS049718. Genomic DNA of regenerated plants from WK21/Nip $\mathrm{F}_{1}$ individuals were extracted from mature leaves of well-grown regenerants. For genotyping of regenerated plants, we used 57 markers designed using simple sequence repeat (SSR) or InDel polymorphisms between WK21 and Nip (Supplementary Figure 1). Among the 57 markers, 22 were randomly distributed on each of 12 chromosomes (McCouch et al., 2002), and 24 were located near the centromere of each chromosome. Each centromere location was based on the Rice Genome Annotation Project database ${ }^{1}$. In

${ }^{1}$ http://rice.plantbiology.msu.edu/cgi-bin/gbrowse/rice/ addition, 12 markers linked to HS loci were used to test zygosity. PCR amplifications for genotyping were performed using GoTaq Green Master Mix (Promega, Madison, WI, United States), with the resulting products subjected to $3 \%$ agarose gel electrophoresis (Supplementary Figure 2). Three genotyping analyses were independently performed.

\section{Immunohistochemical Staining}

To visually detect FDR and SDR in pollen mother cell (PMC) extracted from Nip, WK21, and the WK21/Nip $\mathrm{F}_{1}$ samples (Supplementary Table 4), we performed immunohistochemical staining with anti-O. sativa centromeric histone $\mathrm{H} 3$ (OsCenH3) antibody and anti- $\alpha$-tubulin mouse antibody and observed with a fluorescence microscope, BZ-X800 (Keyence, Osaka, Japan). PMC samples from Nip, WK21, and the $F_{1}$ hybrid were soaked for $20 \mathrm{~min}$ in a fixative consisting of microtubule-stabilizing buffer ( 5 mM PIPES, $0.5 \mathrm{mM} \mathrm{MgSO}_{4}$, and $0.5 \mathrm{mM} \mathrm{EGTA,} \mathrm{pH} \mathrm{7.0)}$ containing $3 \%(\mathrm{w} / \mathrm{v})$ paraformaldehyde and $0.1 \%(\mathrm{v} / \mathrm{v})$ Triton $\mathrm{X}-100$ and then rinsed twice in $1 \times$ PBS buffer for $10 \mathrm{~min}$. In the primary reaction, two primary antibodies were used: antiOsCenH3 rabbit antibody and anti- $\alpha$-tubulin mouse antibody (T6199, Sigma-Aldrich, St. Louis, MO, United States) (Nagaki et al., 2004). A primary antibody solution containing the two antibodies was diluted 200 times with a blocking buffer $[0.4 \mathrm{M}$ Tris- $\mathrm{HCl}$ (pH 7.5), 3.5\% (w/v) NaCl, and 2\% (w/v) BSA]. Fixed anthers were gently dissected on a glass slide using tweezers. Cells from the dissected anthers were suspended in $20 \mu \mathrm{l}$ of $1 \times$ PBS, and covered with a coverslip, and then stored in a freezer $\left(-80^{\circ} \mathrm{C}\right)$. After freezing, the coverslip was removed, $100 \mu \mathrm{l}$ of the primary antibody solution was applied, and the solution was covered by a piece of parafilm $(55 \times 26 \mathrm{~mm})$ to spread the solution. The samples were placed in a moisture chamber to prevent drying and kept at $4^{\circ} \mathrm{C}$ for $14 \mathrm{~h}$. After the primary reaction, the samples were rinsed three times with $1 \times$ PBS for $10 \mathrm{~min}$. Two secondary antibodies were used: Alexa Fluor 488-labeled anti-mouse antibody (\#A-11001: Invitrogen, Carlsbad, CA, United States) and Alexa Fluor 555-labeled antirabbit antibody (\#A20739: Invitrogen). The secondary antibody solution was diluted 200 times with the same blocking buffer used in the primary reaction. After the washing, the PBS buffer was removed from the slides, and then $100 \mu \mathrm{l}$ of secondary antibody solution was applied, and the solution was covered by a piece of parafilm. The slides were placed in a moisture chamber and incubated at $37^{\circ} \mathrm{C}$ for $1 \mathrm{~h}$. After the secondary reaction, the samples were rinsed using the same procedure applied after the primary reaction and then dried. To stain DNAs with minimal fading, $20 \mu \mathrm{l}$ of ProLong Diamond Antifade Mountant with DAPI (Invitrogen) was applied to each slide before observation.

\section{RESULTS}

\section{Pollen Sterility of Interspecific $\mathbf{F}_{\mathbf{1}}$ Hybrids}

Interspecific hybrids between sat-gla are well known to exhibit severe HS that possibly involves more than a dozen HS genes (Sano et al., 1979; Sano, 1983, 1990; Doi et al., 1998, 1999; 
Taguchi et al., 1999; Ren et al., 2006; Zhang et al., 2006; Li et al., 2011; Xu et al., 2014; Yu et al., 2018). An interspecific $\mathrm{F}_{1}$ hybrid of $O$. sativa L. ssp. japonica Nipponbare (Nip) and O. glaberrima Steud. accession IRGC 104038 from Senegal (designated as WK21) produced panicles with sterile seeds as a consequence of aborted pollen and a partially fertile embryo sac (Figure 1A). The mature pollen grains from WK21/Nip $\mathrm{F}_{1}$ were less strongly stained by Lugol's solution, indicating their sterility and inability to accumulate polysaccharides (Figure 1A). To explore the progression of this pollen sterility, we observed developing pollen grains in Nip, WK21, and WK21/Nip $F_{1}$ (Figure 1B). As development continued, pollen grains of both parents first showed evidence of acetocarmine staining at the early binucleate stage and were fully stained at the trinucleate stage (Figure 1B). During the early uninucleate stage of pollen development, most microspores from WK21/Nip $F_{1}$ plants exhibited no prominent differences in size or shape compared with the parents (Figure 1B), but some had abnormal structures, such as a fused form or a larger size than that of normal microspores (Figure 1C). The proportion of standard-shaped microspores in WK21/Nip $\mathrm{F}_{1}$ plants decreased as they developed into pollen (Figure 1B). At the mature stage, normal, round pollen grains had disappeared, and the number of cavitated pollen grains had increased (Figure 1B).

\section{Plant Regeneration From Calli of Interspecific $\mathbf{F}_{\mathbf{1}}$ Hybrids}

In previous research, Kanaoka et al. (2018) successfully rescued microspores at the late uninucleate stage in interspecific hybrid plants (WK21/Nip $F_{1}$ and its reciprocal cross hybrid Nip/WK21 $\mathrm{F}_{1}$ ) to induce calli by the AC method with RI-13 medium. In that study, 98 calli were obtained from 28,181 anthers, which corresponded to induction frequencies of approximately 11 calli from 14,724 Nip/WK21 anthers and 87 calli from 13,457 WK21/Nip anthers (Supplementary Table 1). In the present study, we used the 87 calli derived from WK21/Nip $\mathrm{F}_{1}$ for plant regeneration. The $11 \mathrm{Nip} / \mathrm{WK} 21$ calli (the opposite cross combination to WK21/Nip) were not used because only a single plantlet was generated. Distinct frequencies of callus generation between the two reciprocal hybrids were used to infer whether certain sporophytic influences were due to cytoplasmic or maternal effects of the parental plants. Regeneration of plants from calli was attempted using N6-based medium. We obtained 19 regenerated plantlets from the WK21/Nip $\mathrm{F}_{1}$-anther derived calli (Supplementary Table 1 and Supplementary Figure 3). Thirteen plantlets were regenerated from 23 Nip calli induced with SK-1 medium, whereas no plantlets were regenerated from WK21 calli in this study (Supplementary Table 1). The 19 plantlets from the WK21/Nip $\mathrm{F}_{1}$-anther derived calli were grown in soil; 17 became mature plants, while two died (Supplementary Figure 3). Two phenotypic traits typically different between satgla, namely, leaf smoothness and awn presence, were segregated in the 17 regenerated plants and both parents (Figures 2A,B).

\section{Genotyping of Regenerated Plants}

The 19 plantlets grown as seedlings from callus were genotyped with 22 SSR markers located on the 12 rice chromosomes and polymorphic between the two parents (Supplementary Figures 1, 2). In general, the DH plants obtained via AC had completely homozygous genomes as a result of the doubling of the male gametic genome. Any heterozygotes may have been due to DNA of somatic tissues (e.g., from anther walls) of the $\mathrm{F}_{1}$ hybrid plants, but we could not rule out the possibility of allopolyploids involving both parental genome sets. As shown
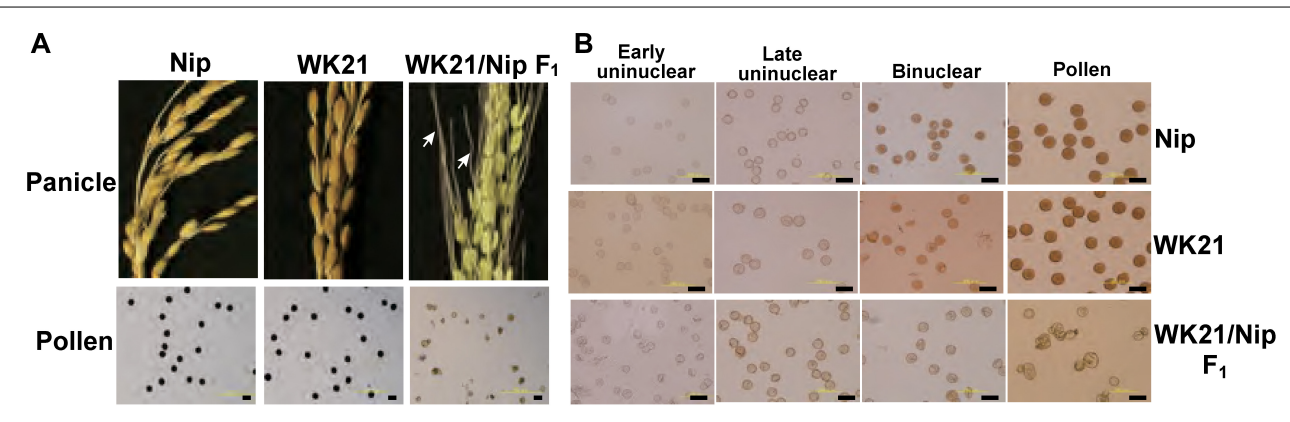

C Early uninuclear of WK21/Nip $F_{1}$
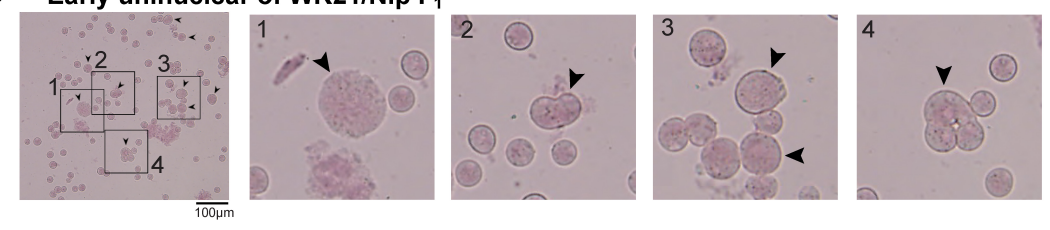

FIGURE 1 | Images of microspores at different developmental stages in Nip, WK21, and WK21/Nip F 1 plants. (A) Panicles and pollen grains of Nip, WK21, and WK21/Nip F 1 plants. Panicles in Nip and WK21 were fertile, while the panicle in WK21/Nip $F_{1}$ was sterile. Awns developed in the interspecific $F_{1}$ hybrid (white arrows) but not in the parents. Pollen grains from Nip and WK21, which were stainable with Lugol's iodine solution, exhibited potential fertility, whereas pollen from WK21/Nip $F_{1}$ was sterile, as reflected by the absence of staining. (B) Microspores at early uninucleate, late uninucleate, binucleate, and trinucleate stages. Microspores were stained with acetocarmine. The black bar in each panel corresponds to $100 \mu \mathrm{m}$. (C) Abnormal microspores in WK21/Nip $\mathrm{F}_{1}$ plants at the early uninucleate stage. Microspores were stained with acetocarmine. Black arrows indicate abnormally shaped microspores. The black bar in each panel corresponds to $100 \mu \mathrm{m}$. 
A

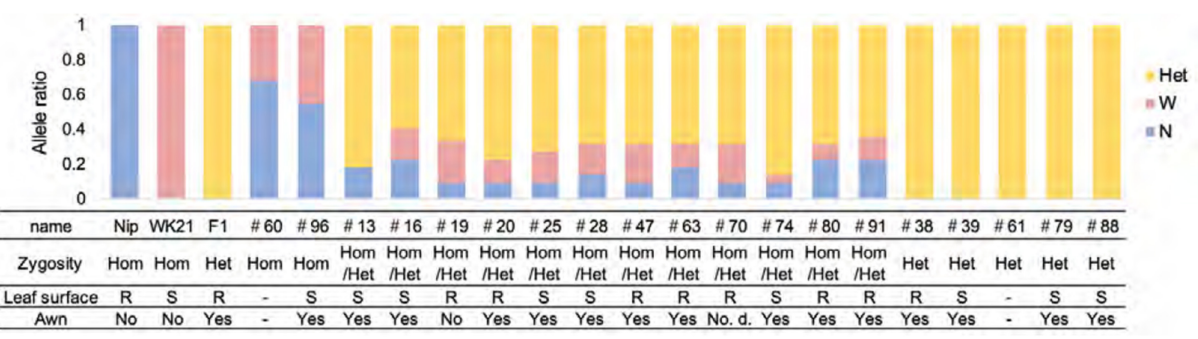

B

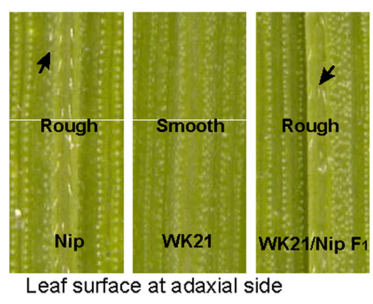

FIGURE 2 | Characteristics of the 19 regenerated plants. (A) Origins and ratios of the alleles in 19 plant genomes regenerated from the calli of WK21/Nip $F_{1}$ hybrids, The origins of the alleles are indicated by blue (N) for homozygous allele of Oryza sativa (Nip), pink $(\mathrm{W})$ for homozygous allele of $O$. glaberrima (WK21), and yellow (Het) for the heterozygous allele. The allelic ratio was calculated with 22 markers used for genotyping (one or two selected from each of 12 chromosomes) detailed in Supplementary Figure 1 and Supplementary Table 2. The state of the leaf surface [rough (R) or smooth (S)] and the presence (yes) or absence (no) of awns (Figure 1A) are also indicated. (B) Leaf surfaces of Nip, WK21, and WK21/Nip $F_{1}$ plants. Surfaces of adaxial sides of Nip and $F_{1}$ leaves were rough because trichomes were present (black arrows), whereas those of WK21 were smooth because trichomes were lacking.

in Figure 2A, genotyping of the 19 plantlets revealed that two plantlets (\#60 and \#96) were completely homozygous (Hom) for either genotype at each marker locus, while five plantlets (\#38, \#39, \#61, \#79, and \#88) were heterozygous (Het) at all loci. The remaining 12 individuals had mixed genomes (Hom/Het) containing both homozygous and heterozygous loci (Figure 2A and Supplementary Table 2). The coexistence of homozygous and heterozygous loci in the plantlets derived from AC has two possible causes: an abnormality of meiosis in the parental plants or fusions between cells containing homozygotes and/or heterozygotes during callus culture. These results are in contrast to the observations of Morinaga and Kuriyama (1957), who did not detect any meiotic anomalies in their cytological study of interspecific hybrids between sat-gla.

\section{Ploidy Analysis of Regenerated Plants}

To examine ploidy levels of the 19 regenerated plantlets obtained from AC, we performed a flow cytometric analysis (Figure 3A). Ploidy levels of the analyzed samples were based on relative fluorescence intensity comparisons with the parental diploid. As shown in Figure 3B, 5 of the 19 plantlets were diploid, and 12 regenerated plants-eight tetraploids, three triploids, and a pentaploid-were polyploid. No haploids were obtained. No apparent relationship was observed between ploidy level and degree of homo- or heterozygosity, but the three triploids were commonly Het plantlets (Figure 2). Among the $12 \mathrm{Hom} / \mathrm{Het}$ plantlets, five were diploid, one was pentaploid, and six were tetraploid (Figure 2). Microscopic observation also supported the results of the flow cytometric analysis: root tip cells from the examined plantlet (\#20) had a chromosome number larger than 40 , compared with 24 chromosomes in the parental sat-gla diploid (Figure 3C). As both the observations for chromosomal numbers did not seem to be perfectly accurate, we could not rule out the presence of aneuploid in the regenerated plants. Unlike AC of intraspecific hybrids, which usually produces $\mathrm{DH}$ plants, $\mathrm{AC}$ of the interspecific sat-gla $\mathrm{F}_{1}$ hybrid resulted in many polyploid regenerants (12/19). These results led us to consider whether microspores from the $\mathrm{F}_{1}$ hybrid were directly responsible for the aberrant ploidy levels.

\section{Origin of the Hom/Het Plants}

We considered three possible causes for the polyploidy of the regenerants. First, the 12 Hom/Het plants (\#13, \#16, $\# 19, \# 20, \# 25, \# 28, \# 47, \# 63, \# 70, \# 74, \# 80$, and \#91) were expected to result from the generation of abnormal tetrads through incomplete meiotic reduction. These meiotic anomalies involve two major arrests of meiotic reduction: FDR and SDR (Jauhar, 2007; De Storme and Geelen, 2013; Han et al., 2018; Figure 4A). FDR is the halt in division of homologous chromosomes after recombination during meiosis I, while SDR is the arrest of the separation of paired sister chromatids during meiosis II (Figure 4A). Either meiotic division restitution produces microspores carrying diploid Hom/Het genomes. Diploid microspores with Hom/Het genomes may be duplicated during callus formation or regeneration processes, resulting in tetraploid Hom/Het plants. In regard to possible causes of incomplete meiotic reduction, we could test whether FDR or SDR was responsible for the Hom/Het plants. Hom/Het plants arising by FDR were expected to exhibit heterozygosity (i.e., both parental sequences) around centromeric regions (De Storme and Geelen, 2013). Because centromeric regions rarely undergo recombination, centromeric regions in paired homologous chromosomes between sat-gla remained heterozygous after meiosis I (Figure 4A). In contrast, Hom/Het plants generated by SDR would have homozygous centromeric regions (i.e., either parental sequence) because of the cancelation of sister-chromatid separation during meiosis II (De Storme and Geelen, 2013; Figure 4A). To distinguish between these two possibilities, the 12 chromosomes of the 12 regenerants were genotyped using centromeric-region-specific SSR and insertion/deletion polymorphism (InDel) primers (McCouch et al., 2002; Supplementary Figure 2 and Supplementary Table 3). Genotyping of the centromeric regions yielded homozygous bands for the Hom plants and heterozygous bands for the Het plants (Figure 4B and Supplementary Table 3). Genotyping of the $12 \mathrm{Hom} / \mathrm{Het}$ plants uncovered two clear patterns: eight individuals (\#13, \#19, \#20, \#25, \#47, \#63, \#74, and \#80) were heterozygous for all the markers in centromeric regions, while the remaining four individuals (\#16, \#28,\#70, and 


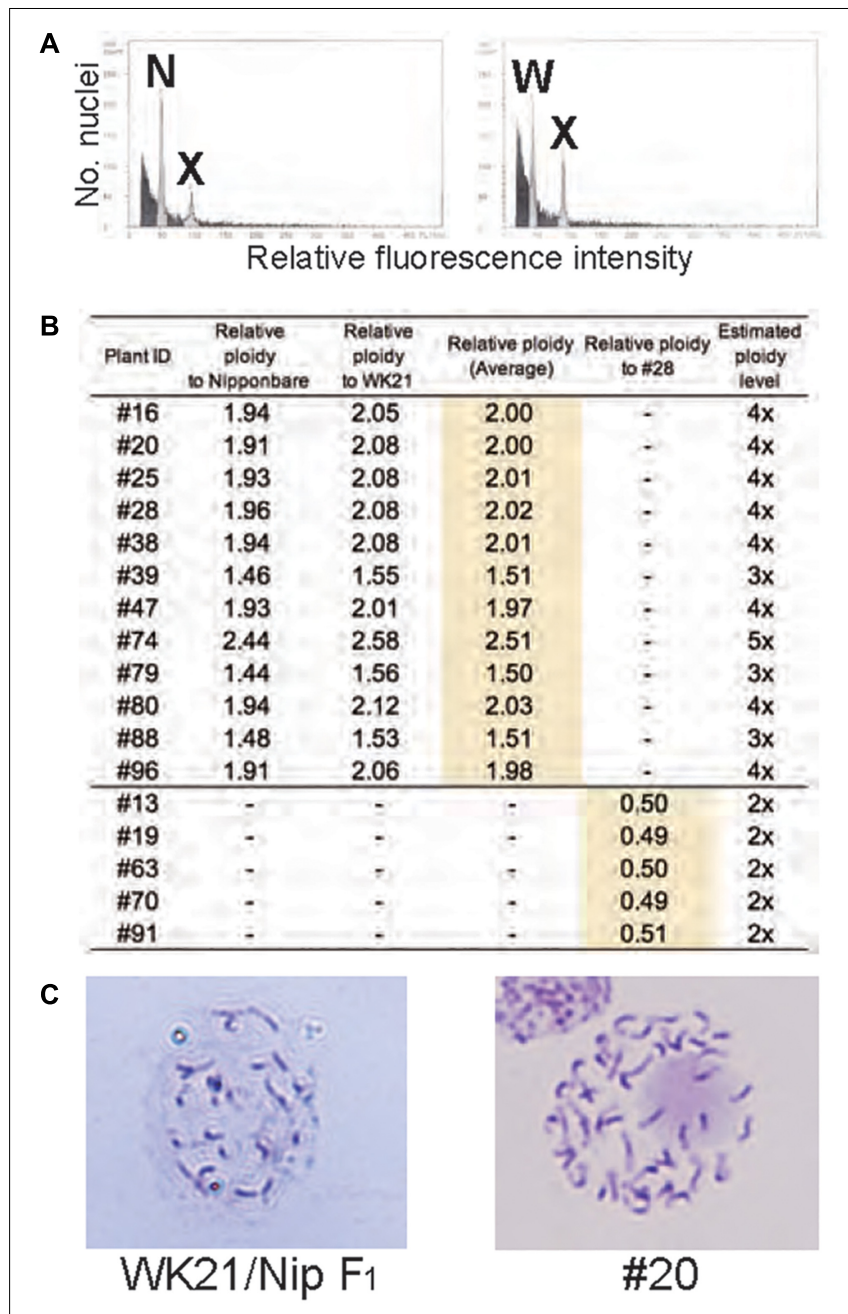

FIGURE 3 | Ploidy analyses of somatic cells of regenerated plants based on flow cytometry (FCM) and Giemsa staining. (A) FCM-based ploidy analysis. Left: FCM histogram of samples of Nip and plant \#20 showing two peaks $-\mathrm{N}$ (derived from the Nip genome) and X (derived from the \#20 genome). Right: FCM histogram showing two peaks $-W$ (from WK21) and X. The ploidy level of \#20 was determined by comparing peak $X$ with peaks $N$ and $W$ from the diploid parental lines. (B) Ploidy levels of regenerated plants estimated from fluorescence intensity peak ratios. Ploidy levels of regenerated plants were based on relative fluorescence intensities of nuclei in Nip and WK21 cells. Diploid ploidy levels estimated by this method were validated by comparison with regenerated plant \#28, which was determined to be tetraploid. (C) Giemsa staining of mitotic cells. Left: mitotic cell from the root tip of a WK21/Nip $F_{1}$ plant. The number of chromosomes in the cell appears to be a half that of a \#20 plant. Right: mitotic cell from the root tip of a \#20 plant regenerated from WK21/Nip $F_{1}$. More than 40 chromosomes are visible.

\#91) were homozygous (Figure 4B and Supplementary Table 3). These results suggest that the first eight Hom/Het plants resulted from FDR and that the latter four plants were derived from SDR. In Figure 1C, the unusual shapes of microspores with a possible association with anomaly meiosis were shown. To verify the occurrence of abnormalities at meiosis in the interspecific $\mathrm{F}_{1}$ hybrid between sat-gla, we observed PMCs from Nip, WK21, and these interspecific F1 hybrid (Figures 4C,D and Supplementary
Table 4). Certain numbers of PMCs (4/20 for meiosis I and 3/25 for meiosis II) in the interspecific $\mathrm{F}_{1}$ hybrid retained abnormal meiotic divisions, but not in the parents (Supplementary Table 4). Normal bivalent chromosomes observed at diplotene in meiosis I are necessary for reduction division, which leads to meiosis II, whereas univalent chromosomes in meiosis I are unable to undergo normal division, resulting in loss of meiosis I. As shown on the left side of Figure 4C, immunochemical staining with anti-OsCenH3 rabbit antibody revealed a numerous pairs of centromeric signals, which implies alignment of bivalent chromosomes at diplotene in PMCs. In the interspecific $\mathrm{F}_{1}$ hybrid, the diplotene sample exhibited unpaired centromeric signals that were given by the presence of univalent chromosomes (right side of Figure 4C). During anaphase II, we also observed unequal division, in which spindle fibers with $\alpha$-tubulin were not equally formed in dividing cells (right side of Figure 4D) relative to normal division (left side of Figure 4D). These observations in PMCs of the interspecific $F_{1}$ hybrid support the occurrence of FDR and SDR in meiosis I and II, respectively.

Second, five Het plants corresponding to three triploids (\#39, $\# 79$, and \#88), one tetraploid (\#38), and one missing (\#61) obviously contained both parental genomes (Figure $\mathbf{2 A}$ and Supplementary Table 2). PMCs that failed to undergo both divisions at meiosis I and II may not have formed tetrads. The occurrence of both division restitutions in a single meiocyte may therefore have given rise to tetraploid Het plants; however, making an assumption about whether the heterozygotic status of the triploids was due to simple aberrant meiosis or a complex process mediated by other factors is difficult. Third, in the Hom plants (\#60 and \#96), \#96 with tetraploid genome may have arisen by haploid gamete doubling, but we could not ascertain exactly when doubling occurred during the AC procedure (Figure 2A).

\section{Fertility and HS Locus Genotypes of Regenerated Plants}

Among the 19 plantlets obtained from AC, 17 grew to maturity, while two (\#60 and \#61) died at the seedling stage. Of the surviving regenerated plants, the five tetraploid ones (\#20, \#25, $\# 38$, \#47, and \#80) generated seeds (Figure 5). More specifically, the five partially fertile tetraploid plants comprised four Hom/Het plants and one Het plant (Figures 2A, 5). The partial fertility of each of these five plants could not be determined because they had inherited the shattering trait from their parent O. glaberrima WK21; however, two regenerated plants, \#38 and \#80, produced a relatively higher number of seeds. To confirm that HS had been overcome in the regenerants, the 17 regenerants were genotyped using 12 SSR primers linked to known HS loci (Kanaoka et al., 2018). As shown in Figure 5, plant \#96 was homozygous for alleles from either of the two parents at each SSR locus. In the four Het plants (\#38, \#39, \#79, and \#88), the $H S$ locus-specific SSR markers were all heterozygous (Figure 5 and Supplementary Table 5). The Hom/Het plants were mixed, carrying both homozygotic and heterozygotic loci (Figure 5 and Supplementary Table 5). The three fertile tetraploid plants, \#25, $\# 38$, and \#80, were heterozygous at more than eight HS loci, a situation that would have caused sterility if these plants had been 
A

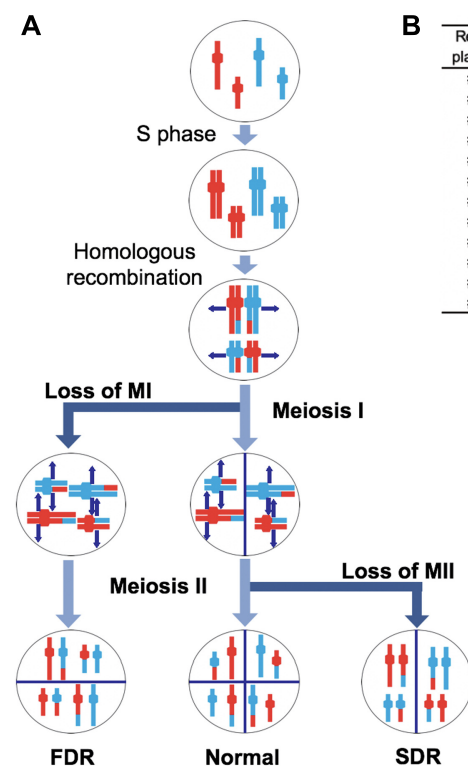

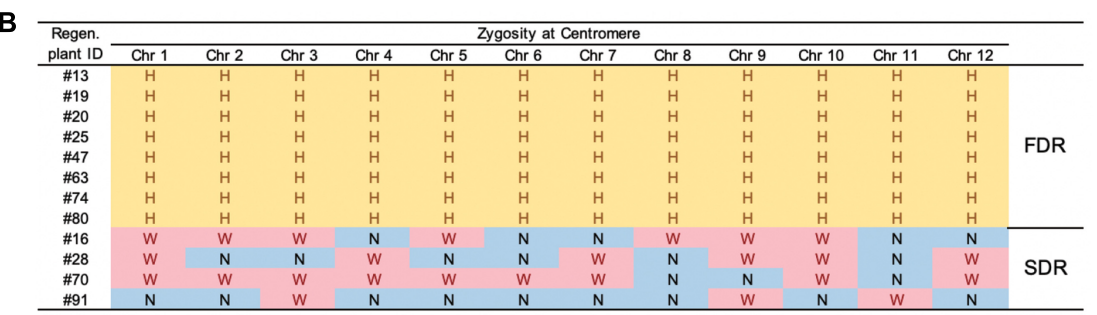

C
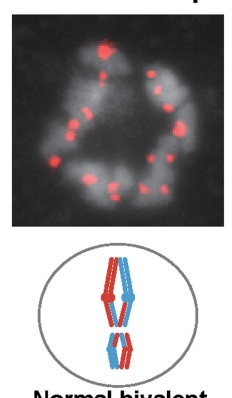

Normal bivalent
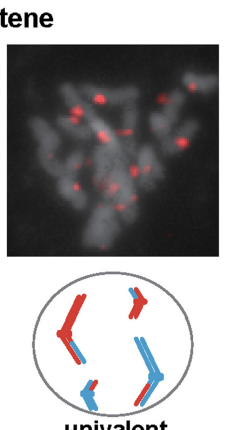

D
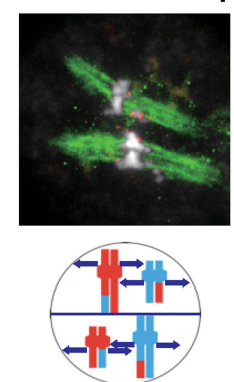

Normal division
Anaphase II

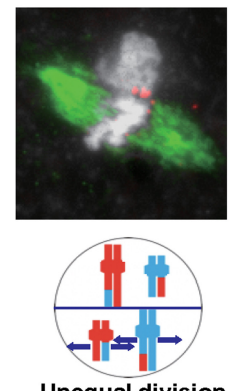

FIGURE 4 | Meiotic anomalies associated with FDR and SDR in WK21/Nip F . (A) Schematic diagram of chromosomal separations following normal, FDR, and SDR meiotic events. The three different chromosomal separation pathways following normal, FDR, and SDR events during meiotic division are based on De Storme and Geelen (2013). In the normal situation, bivalent homologous chromosomes separate after recombination at the end of meiosis I, with the sister chromatids remaining attached at the beginning of meiosis II and then separating. In FDR, homologous chromosomes fail to separate at the end of meiosis I, resulting in homologous chromosomes in the gametes. SDR bypasses meiosis II, and sister chromatids are distributed into gametes. FDR and SDR lead to centromeric regions (shown as knobs) that are respectively heterozygous or homozygous between homologous chromosomes. Red and blue are used to indicate the parental origin of chromosomal regions. (B) Genetic zygosities of centromeric regions of the 12 chromosomes of 12 regenerated plants and detection of FDR and SDR. Markers in centromeric regions (two of each chromosome) used in this analysis are detailed in Supplementary Figure $\mathbf{1}$ and Supplementary Table 3. In the table, the zygosities of the 12 centromeres are indicated by "N" for homozygous centromeres from O. sativa (Nip), "W" for homozygous centromeres for O. glaberrima (WK21), or "H" for heterozygous centromeres. (C) Immunohistochemical detection of normal and anomalous gametes during meiosis I in WK21/Nip $\mathrm{F}_{1}$. Using anti-OsCenH3 antibody, centromeric regions were observed in chromosomes at diplotene in meiosis I in PMCs from WK21/Nip $F_{1}$. Left: detection of paired signals (red spots) from centromeres at diplotene in a PMC, implying normal bivalent chromosomes (white portions). Right: non-aligned, dispersed centromeric signals, indicative of univalent chromosomes. (D) Immunohistochemical detection of normal and anomalous gametes during meiosis II of WK21/Nip $F_{1}$. Using anti- $\alpha$-tubulin mouse antibody, spindle fiber formation (green zone) was observed at anaphase II in PMCs from WK21/Nip F . During normal anaphase II, sister chromatids (white zone) prepared to move toward opposite poles of the cell to generate haploid gametes. Left: normal division, showing movement of sister chromatids to the poles via the spindle fibers in both compartments as monitored using $\alpha$-tubulin antibody. Right: unequal division in a PMC. In the upper compartment, no $\alpha$-tubulin was observed, and sister chromatids were unable to separate and move to the poles; in contrast, the movement of sister chromatids along spindle fibers was apparent in the lower compartment.

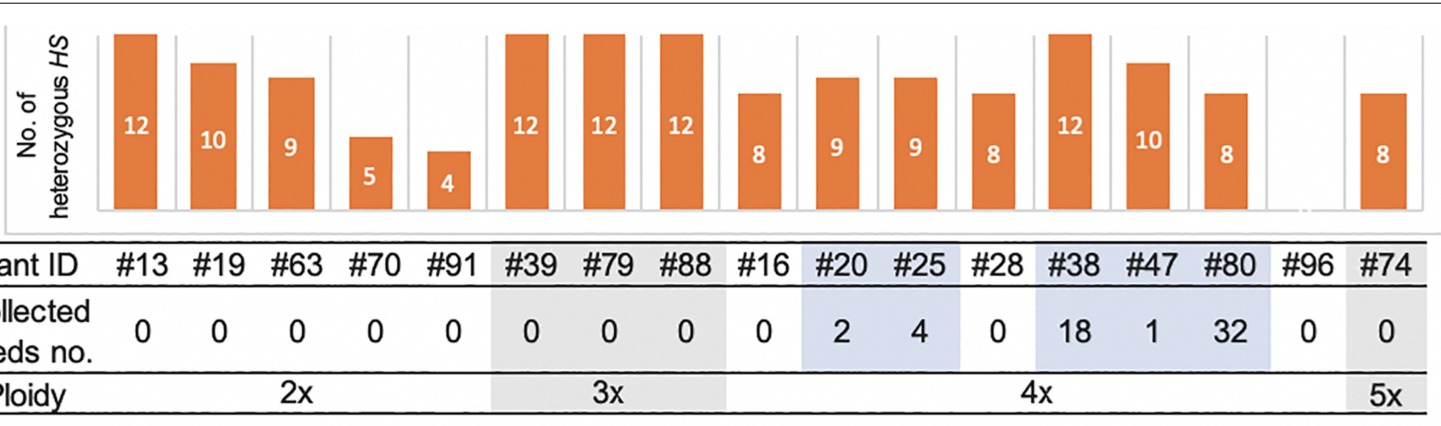

FIGURE 5 | The numbers of heterozygous loci of the $12 \mathrm{HS}$ loci in the genomes of 17 regenerated plants and collected seeds and ploidy. The numbers of the heterozygous HS loci were examined by genotyping with the DNA markers of the 12 HS loci. The details of markers used in this analysis are listed in Supplementary Figure 1 and Supplementary Table 5. The number of collected seeds and ploidy of each regenerated plant are indicated below. Five fertile plants highlighted with pale blue had seeds, which were all tetraploid. 
diploid. Our results are in agreement with the observations of Gopalakrishnan et al. (1964) and Oka (1968) that the tetraploidy of the interspecific hybrid allowed escape from HS.

\section{Phenotypes of Fertile Tetraploids}

The self-pollinated progenies of the three fertile tetraploid lines, RP2-25 (from \#25), RP2-38 (from \#38), and RP2-80 (from \#80), were examined in terms of 20 traits (Table 1). Averages of pollen fertilities in the RP2 three lines were ranged from 5.8 to $39.0 \%$ (Table 1), and most of the individual plants could produce somehow partially normal pollens except one plant (Supplementary Table 6). In terms of the seed set rates, their averages were accounted for further low from 0.1 to $8.0 \%$ with large standard deviations (Table 1). These seed set rates resulted from only one or two individuals with fertility (0.5-40\%) and the other plants were sterile (Supplementary Table 6). The HS loci might explain the difference between fertile and sterile plants, as shown in a partially fertile plant (\#6) in the RP2-38 line, which possessed the WK21 homozygous allele at the $S 34(t)$ locus in the tetraploid genome (Supplementary Table 6). However, it is difficult to explain why parental tetraploid plants were partially fertile for this reason.

Seed sizes from $\# 80$ plants were larger than those of the parents: 1.42- and 1.34-fold longer and 1.33- and 1.38-fold wider relative to Nip and WK21, respectively (Table 1). Likewise, fertile plants in the next generation (RP3) also produced bigger seeds (Table 1). Of the five fertile tetraploid plants, the fertilities of plants from $\# 25$, \#38, and \#80 were passed along to subsequent generations. These plants thus appeared to have overcome the HS between sat-gla. Self-pollinated progenies of three fertile tetraploid lines, RP2-25 (from \#25), RP2-38 (from \#38), and RP280 (from \#80), were obtained and phenotypically compared with their parental lines, Nip and WK21. The following characters were measured: seed length, seed width, plant height, leaf length, leaf breadth, ligule length, and pistil color (Table 1). Most phenotypes in the second generation derived from the three tetraploid regenerated lines were larger than those of their parents (Table 1), thus reflecting typical tetraploid vigor. In regard to pistil color, the blackish purple pistils of WK21 were expressed in the $\mathrm{F}_{1}$ generation and RP2-25 and RP2-38 lines, while the white pistils of Nip were inherited by the RP2-80 line (Table 1).

\section{DISCUSSION}

\section{Production of Plants From Hybrids Between sat-gla by AC}

Because of gamete sterility, progenies cannot be generated from interspecific hybrids of sat-gla (Oka, 1957; Sano et al., 1979). In this study, we successfully regenerated plants from callus induced by culturing sterile microspores of interspecific hybrid plants without the recombinant DNA techniques. Five of the 19 regenerated plants produced seeds. According to Kanaoka et al. (2018), the essential factor for obtaining plants from interspecific hybrids with strong HS is the use of callus obtained by culturing anthers with microspores at the uninucleate stage. Uninucleatestage microspores are required for embryogenesis not only in rice but also in wheat (Hassawi and Liang, 1990). In grape (Gribaudo et al., 2004), barley (Hoekstra et al., 1992), and Brassica napus (Telmer et al., 1992), embryoid bodies can also be differentiated directly from uninucleate microspores. Microspores appear to lose their embryogenic (or callus formation) ability after the uninucleate stage, and differentiation into pollen then irreversibly progresses (Kinoshita et al., 2000). Even in the interspecific hybrid between sat-gla exhibiting HS, microspore decay had not yet begun in uninucleate microspores (Figures 1B,C, 6A). This stage is a crucial point for rescuing microspores to obtain plants from AC of interspecific hybrids (Kinoshita et al., 2000; Figure 6A).

Diploid plants differentiated through AC usually have complete homozygosity because haploid male gametes are spontaneously doubled during the differentiation process. In this study, only two DH lines were detected among the 19 regenerated plants (Figure 2A). The other individuals differed in terms of zygosity and ploidy level from ordinal diploid DH lines (Table 2). We could thus readily infer that abnormalities occurred during male gametophyte formation in the interspecific hybrid. We therefore examined anomalies related to male gametophyte formation from two perspectives, genomic zygosity and ploidy level.

\section{Variations in Zygosity}

Individuals derived by $\mathrm{AC}$ of the interspecific hybrid were divided into three groups on the basis of zygosity: (1) Hom individuals having completely homozygous genomes, (2) Het individuals with complete heterozygosity, and (3) Hom/Het plants having both homozygous and heterozygous genomic regions (Figure 2A). The first group presumably originated from cases in which the haploid genome of a gamete spontaneously doubled during callus formation or regeneration in an ACderived rice plant (Rout et al., 2016; Naik et al., 2017). The complete heterozygosity of plants in the second group had two possible causes (Huang et al., 1997): (a) callus formation of the $F_{1}$ somatic cells, such as anther wall cells, and (b) callus formation occurring in the PMC harboring the paired genomes before the first meiotic division. The third group, which included both homozygous and heterozygous regions, may have emerged after meiotic recombination (Pinson and Rutger, 1993). Tetraploid Hom/Het plants may have been derived from microspores in which the diploid genome was doubled during callus development, while diploid Hom/Het plants may have arisen from microspores formed from callus without genome doubling. AC of rice intraspecific hybrids rarely produced Hom/Het plants, which were derived from diploid microspores (Grewal et al., 2011).

\section{Meiotic Anomalies}

In $\mathrm{AC}$ of rice, plant differentiation occurs via callus. The most active period of callus formation during pollen development corresponds to the middle to late uninucleate microspore stage. We observed abnormal forms of microspores at the uninuclear stage in the interspecific hybrid, such as microspores that were twice the size of normal ones and fusions of two microspores (Figure 1C). Flow cytometry and chromosome observations 
TABLE 1 | The features of the progenies (RP2-25, -38, -80) from the fertile regenerated plants, 25, 38, and 80, respectively.

\begin{tabular}{|c|c|c|c|c|c|c|c|c|c|c|c|c|c|c|c|c|c|c|c|c|}
\hline \multirow{2}{*}{$\begin{array}{l}\text { Plant } \\
\text { materials }\end{array}$} & \multirow{2}{*}{$\begin{array}{l}\text { Pollen } \\
\text { fertility } \\
(\%)\end{array}$} & \multirow{2}{*}{$\begin{array}{l}\text { Seed set } \\
\text { rate (\%) }\end{array}$} & \multicolumn{2}{|c|}{ Seed size $^{2}(\mathrm{~mm})$} & \multicolumn{2}{|c|}{ Seed size $^{3}(\mathrm{~mm})$} & \multirow{2}{*}{$\begin{array}{c}\text { Plant } \\
\text { height } \\
\text { (cm) }\end{array}$} & \multicolumn{4}{|c|}{ Leaf length (cm) } & \multicolumn{4}{|c|}{ Leaf breadth $(\mathrm{cm})$} & \multicolumn{4}{|c|}{ Ligule length (cm) } & \multirow{2}{*}{$\begin{array}{c}\text { Color } \\
\text { of } \\
\text { pistils }\end{array}$} \\
\hline & & & Length & Width & Length & Width & & $\begin{array}{l}\text { Flag } \\
\text { leaf }\end{array}$ & Flag- $1^{4}$ & Flag-2 & Flag-3 & $\begin{array}{l}\text { Flag } \\
\text { leaf }\end{array}$ & Flag-1 & Flag-2 & Flag-3 & $\begin{array}{l}\text { Flag } \\
\text { leaf }\end{array}$ & Flag-1 & Flag-2 & Flag-3 & \\
\hline $\mathrm{RP} 2-25^{1}(n=4)$ & $\begin{array}{c}5.8 \\
\pm \\
1.8\end{array}$ & $\begin{array}{c}0.1 \\
\pm \\
0.2\end{array}$ & n.d. & & n.d. & & $\begin{array}{c}122.9 \\
\pm \\
6.6\end{array}$ & $\begin{array}{c}28.0 \\
\pm \\
7.7\end{array}$ & $\begin{array}{l}59.0 \\
\pm \\
13.2\end{array}$ & $\begin{array}{c}77.7 \\
\pm \\
8.6\end{array}$ & $\begin{array}{c}81.6 \\
\pm \\
4.2\end{array}$ & $\begin{array}{c}2.13 \\
\pm \\
0.07\end{array}$ & $\begin{array}{c}1.71 \\
\pm \\
0.09\end{array}$ & $\begin{array}{c}1.47 \\
\pm \\
0.13\end{array}$ & $\begin{array}{c}1.50 \\
\pm \\
0.07\end{array}$ & $\begin{array}{c}0.65 \\
\pm \\
0.16\end{array}$ & $\begin{array}{c}1.97 \\
\pm \\
0.42\end{array}$ & $\begin{array}{c}3.43 \\
\pm \\
1.08\end{array}$ & $\begin{array}{c}2.94 \\
\pm \\
0.86\end{array}$ & $\begin{array}{c}\text { Blackish } \\
\text { purple }\end{array}$ \\
\hline $\mathrm{RP} 2-38(n=6)$ & $\begin{array}{c}16.5 \\
\pm \\
20.1\end{array}$ & $\begin{array}{c}8.0 \\
\pm \\
14.5\end{array}$ & n.d. & & $\begin{array}{c}8.7 \\
\pm \\
0.5\end{array}$ & $\begin{array}{c}2.9 \\
\pm \\
0.3\end{array}$ & $\begin{array}{c}130.7 \\
\pm \\
13.9\end{array}$ & $\begin{array}{c}26.7 \\
\pm \\
14.2\end{array}$ & $\begin{array}{l}55.6 \\
\pm \\
21.1\end{array}$ & $\begin{array}{c}78.5 \\
\pm \\
6.8\end{array}$ & $\begin{array}{c}81.5 \\
\pm \\
8.7\end{array}$ & $\begin{array}{c}1.94 \\
\pm \\
0.25\end{array}$ & $\begin{array}{c}1.56 \\
\pm \\
0.29\end{array}$ & $\begin{array}{c}1.51 \\
\pm \\
0.13\end{array}$ & $\begin{array}{c}1.49 \\
\pm \\
0.11\end{array}$ & $\begin{array}{c}0.82 \\
\pm \\
0.29\end{array}$ & $\begin{array}{c}1.63 \\
\pm \\
0.34\end{array}$ & $\begin{array}{c}2.62 \\
\pm \\
0.67\end{array}$ & $\begin{array}{c}2.58 \\
\pm \\
0.41\end{array}$ & $\begin{array}{c}\text { Blackish } \\
\text { purple }\end{array}$ \\
\hline $\mathrm{RP} 2-80(n=5)$ & $\begin{array}{c}39.0 \\
\pm \\
20.7\end{array}$ & $\begin{array}{c}0.6 \\
\pm \\
1.3\end{array}$ & $\begin{array}{c}9.1 \\
\pm \\
0.5\end{array}$ & $\begin{array}{c}3.6 \\
\pm \\
0.3\end{array}$ & $\begin{array}{c}9.0 \\
\pm \\
0.2\end{array}$ & $\begin{array}{c}4.0 \\
\pm \\
0.3\end{array}$ & $\begin{array}{c}120.3 \\
\pm \\
3\end{array}$ & $\begin{array}{c}16.3 \\
\pm \\
8.4\end{array}$ & $\begin{array}{c}43.4 \\
\pm \\
7.3\end{array}$ & $\begin{array}{c}75.1 \\
\pm \\
5.7\end{array}$ & $\begin{array}{c}78.8 \\
\pm \\
6.8\end{array}$ & $\begin{array}{c}1.64 \\
\pm \\
0.61\end{array}$ & $\begin{array}{c}1.86 \\
\pm \\
0.26\end{array}$ & $\begin{array}{c}1.87 \\
\pm \\
0.10\end{array}$ & $\begin{array}{c}1.67 \\
\pm \\
0.16\end{array}$ & $\begin{array}{c}0.47 \\
\pm \\
0.14\end{array}$ & $\begin{array}{c}0.96 \\
\pm \\
0.29\end{array}$ & $\begin{array}{c}1.70 \\
\pm \\
0.31\end{array}$ & $\begin{array}{c}1.52 \\
\pm \\
0.21\end{array}$ & White \\
\hline $\begin{array}{l}\text { WK21 (seed } \\
\text { parent) }\end{array}$ & $\begin{array}{c}90.4 \\
\pm \\
1.6\end{array}$ & $\begin{array}{c}91.5 \\
\pm \\
1.1\end{array}$ & $\begin{array}{c}6.8 \\
\pm \\
0.4\end{array}$ & $\begin{array}{c}2.6 \\
\pm \\
0.3\end{array}$ & - & - & 115.1 & 18.6 & 40.2 & 69.2 & 61.3 & 1.60 & 1.40 & 1.25 & 1.45 & 0.40 & 0.50 & 0.55 & 0.70 & $\begin{array}{c}\text { Blackish } \\
\text { purple }\end{array}$ \\
\hline $\begin{array}{l}\text { Nipponbare } \\
\text { (pollen parent) }\end{array}$ & $\begin{array}{c}89.7 \\
\pm \\
1.3\end{array}$ & $\begin{array}{c}85.0 \\
\pm \\
1.1\end{array}$ & $\begin{array}{c}6.4 \\
\pm \\
0.4\end{array}$ & $\begin{array}{c}2.7 \\
\pm \\
0.2\end{array}$ & - & - & 97.9 & 18.4 & 33.2 & 56.7 & 69.5 & 1.45 & 1.43 & 1.30 & 1.20 & 0.40 & 0.85 & 1.00 & 1.30 & White \\
\hline WK21/Nip $\mathrm{F}_{1}$ & 0.0 & 0.0 & - & - & - & - & - & - & - & - & - & - & - & - & - & - & - & - & - & $\begin{array}{c}\text { Blackish } \\
\text { purple }\end{array}$ \\
\hline
\end{tabular}

${ }^{1} R P 2$ is the next generation of the regenerated plants from AC. ${ }^{2}$ The seeds were ones (RP2) from the fertile regenerated plants. ${ }^{3} T$ he seeds were ones (RP3) from the seeds of the progeny (RP2) of the regenerated plants. ${ }^{4}$ Flag-1, Flag-2, and Flag-3 mean one, two, and three leaves previous to the flag leaf emerged, respectively. The measurements of the 20 characteristic items were performed with four, six, and five progenies from the three tetraploid plants, RP2-25, RP2-38, and RP2-80, respectively. ${ }^{5}$ Three traits of $F_{1}$ were references of those we have previously observed plants, but we did not measure plants with the same conditions as listed in this table. 

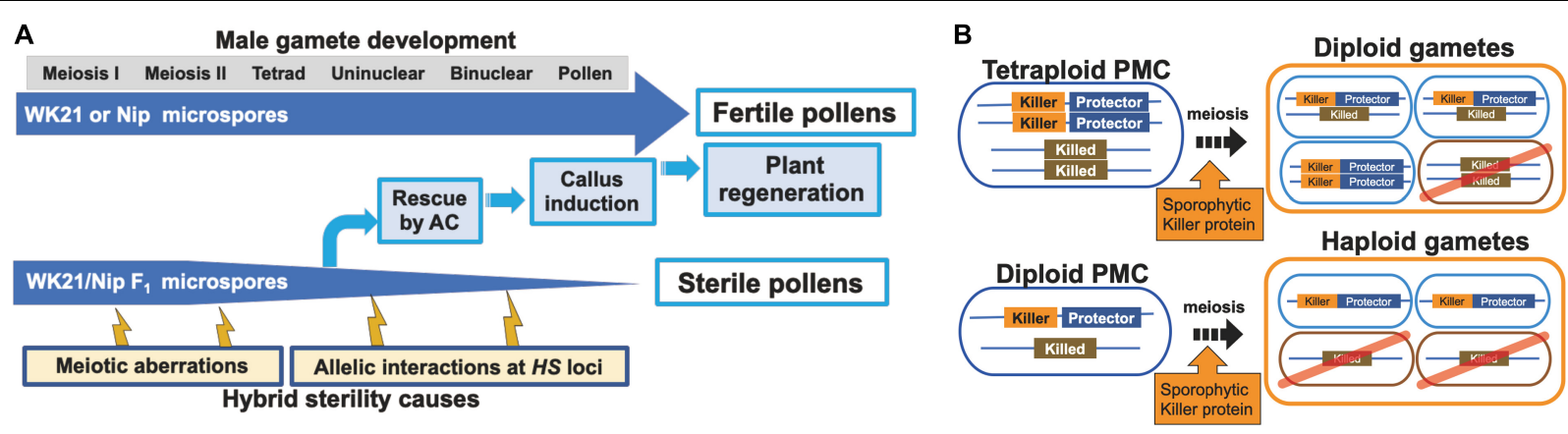

FIGURE 6 | Models of processes of hybrid sterility and its circumvention. (A) A new model of hybrid sterility and plant regeneration by AC during microspore development in WK21/Nip F . Microspores of WK21/Nip $F_{1}$ do not develop into pollen because of HS due to 1) meiotic aberrations and 2) allelic interactions at HS loci. (B) Higher rates of fertile gametes in tetraploids compared with diploids according to the killer-protector model. Under the killer-protector model of HS, the killer protein has a sporophytic effect on gametes during microspore development after meiosis, but the gamete expressing the protector protein is not killed. In the case of a heterozygous tetraploid plant, which contains two killer-protector alleles and two killed alleles, three-quarters of the gametes possess protector alleles. In the case of a heterozygous diploid plant, only half of the gametes carry a killer-protector allele. In theory, a heterozygous tetraploid thus produces $25 \%$ more surviving gametes than does a heterozygous diploid plant.

TABLE 2 | The genetic properties and fertility of the 19 regenerated plants.

\begin{tabular}{|c|c|c|c|c|c|}
\hline \multirow[t]{2}{*}{ Regenerated plant ID } & \multirow[t]{2}{*}{ Ploidy } & \multicolumn{2}{|c|}{ Genetic zygosity } & \multirow[t]{2}{*}{ Types of meiotic aberration } & \multirow[t]{2}{*}{ Collected seed number } \\
\hline & & Non-centromeric region & Centromeric region & & \\
\hline$\# 60$ & - & Hom & Hom & Haploid gamete & 0 \\
\hline \#96 & $4 x$ & Hom & Hom & Haploid gamete & 0 \\
\hline$\# 13$ & $2 x$ & Hom/Het & Het & FDR & 0 \\
\hline \#19 & $2 x$ & Hom/Het & Het & FDR & 0 \\
\hline \#20 & $4 x$ & Hom/Het & Het & FDR & 2 \\
\hline \#25 & $4 x$ & Hom/Het & Het & FDR & 4 \\
\hline \#47 & $4 x$ & Hom/Het & Het & FDR & 1 \\
\hline$\# 63$ & $2 x$ & Hom/Het & Het & FDR & 0 \\
\hline$\# 74$ & $5 x$ & Hom/Het & Het & FDR & 0 \\
\hline \#80 & $4 x$ & Hom/Het & Het & FDR & 32 \\
\hline \#16 & $4 x$ & Hom/Het & Hom & SDR & 0 \\
\hline \#28 & $4 x$ & Hom/Het & Hom & SDR & 0 \\
\hline \#70 & $2 x$ & Hom/Het & Hom & SDR & 0 \\
\hline \#91 & $2 x$ & Hom/Het & Hom & SDR & 0 \\
\hline \#38 & $4 x$ & Het & Het & & 18 \\
\hline \#39 & $3 x$ & Het & Het & & 0 \\
\hline$\# 61$ & - & Het & Het & & 0 \\
\hline \#79 & $3 x$ & Het & Het & & 0 \\
\hline \#88 & $3 x$ & Het & Het & & 0 \\
\hline
\end{tabular}

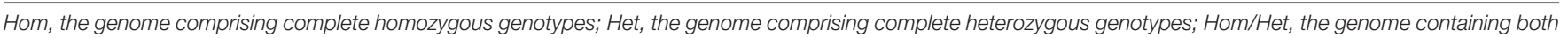

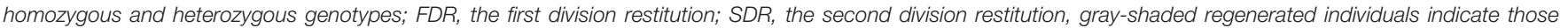
producing fertile seeds. \#60 and \#61 died at the seeding stage before analysis of FCM.

demonstrated that many regenerated plants were tetraploid, triploid, or pentaploid (Figure 3). These observations suggest that meiotic anomalies of interspecific hybrids lead to insufficient microspore separation and occasional fusion at the tetrad stage. Our genomic analysis revealed that 12 of 19 regenerated plants resulted from abnormalities in division after meiotic recombination (Figure 4B and Supplementary Table 3). Meiotic divisions were also observed by immunohistochemical staining for OsCenH3 and $\alpha$-tubulin (Figures 4C,D and Supplementary Table 4). Both anomalies in the first and second divisions during meiosis were only detected in the PMC samples from the interspecific $\mathrm{F}_{1}$ hybrid, but not in the PMC samples from the parents (Supplementary Table 4). In the interspecific F1 hybrid, the meiotic anomalies involved cancelation of either the first or second division, thereby leading to diploid gametophyte generation and subsequent polyploid formation during plant regeneration from callus (Figure 4; Jauhar, 2007; De Storme and Geelen, 2013; Han et al., 2018). In some cases, neither the first nor the second division occurred, and the tetraploid gametes were able to develop into callus and differentiate directly 
into plants. We were able to deduce the mechanisms associated with the occurrence of tetraploidy based on meiotic anomalies in the interspecific hybrid. Although a detailed explanation for how triploid and pentaploid plants were generated from AC of the hybrid could not be determined, we assumed that triploid and pentaploid plants might be attributable to the unusual fusion of microspores at the tetrad stage after the second division in meiosis.

Because most male gametes in $\mathrm{F}_{1}$ hybrids between sat-gla should decay during pollen development, determination of the genome harbored by each gamete has not been possible. In this study, we demonstrated that genetic characterization of male gametes in hybrid plants between sat-gla is feasible by rescuing abortive microspores with $\mathrm{AC}$ and allowing them to differentiate into plants. More than a dozen HS loci between sat-gla can act on male and/or female gametes and, in particular, cause male gametes to become sterile (Koide et al., 2008; Garavito et al., 2010; Kanaoka et al., 2018). Although HS genes are widely known to be responsible for HS, our study has clearly shown that meiotic anomalies occur before these genes act (Figure 6A). Alternatively, meiotic anomalies may also be one of the causes of HS that collapses the gamete genome (Figure 6A). Future required work includes a detailed analysis of meiotic anomalies occurring in PMCs in hybrids and clarification of the relationship between the mechanism of non-segregation of the first and second divisions and gamete decay.

\section{Ploidy Levels and HS Avoidance Mechanisms}

Among the plants derived from AC, all five plants that produced seeds had tetraploid and heterozygous genomic regions. Four of these five fertile plants were Hom/Het, and one was a completely Het individual. The four Hom/Het plants also had many alleles of HS loci as heterozygote. Gametes possessing a killed allele at an HS locus will not survive (Sano et al., 1979; Jones et al., 1997). The existence of multiple $H S$ loci reduces the number of surviving gametes by one-half per each additional locus. More than a dozen HS loci have been found between sat-gla, and most of the hybrid gametes are sterile or die (Sano et al., 1979; Sano, 1983, 1990; Doi et al., 1998, 1999; Taguchi et al., 1999; Ren et al., 2006; Zhang et al., 2006; Li et al., 2011; Xu et al., 2014; Yu et al., 2018). In the present study, partially fertile plants were obtained from a tetraploid with heterozygous $H S$ alleles. Except for backcross lines with either parent, we never obtained such fertile plants from self-pollinated interspecific $\mathrm{F}_{1}$ hybrids between sat-gla (Figure 5 and Table 2). Among the 19 regenerated plants from AC, in contrast, we obtained five partially fertile plants, all of which were tetraploids. Polyploidization may thus be a way to remove the barrier between the two species.

The HS genes responsible for the $S 1$ locus between sat-gla have recently been isolated (Xie et al., 2017, 2019; Koide et al., 2018), thus allowing the mechanism of the killer-protector system to be elucidated. In this system, a killer gene is linked to a protector gene that protects gametes from the action of the former (Yang et al., 2012; Ouyang and Zhang, 2013; Zhu et al., 2017; Xie et al., 2019). When a protector gene is present in the same gamete, the killer allele is protected against the killer protein itself. If so, the killer gene at the HS locus appears to sporophytically act on other gametes (not encased in the same membrane) that do not have a protector after separation into a tetrad. Tetraploids from sat-gla hybrids are likely fertile because three-quarters of diploid gametes from a tetraploid plant contain both killer and protector alleles (Figure 6B). In contrast, a diploid plant derived from hybrids between sat-gla produces haploid gametes, a half of which may contain both killer and protector alleles (Figure 6B). Although the different killer-protector allele ratios in gametes may reflect the distinct seed fertilities of the tetraploid vs. the diploid, the killer-protector system is not the only explanation for these observations.

\section{Characteristics of Fertile Plants Obtained From AC}

Five lines of partially fertile tetraploids, \#20, \#25, \#38, \#47, and $\# 80$, were obtained by $\mathrm{AC}$ of the interspecific hybrid of satgla (Figure 5 and Table 2). Fertility in these regenerated plants was a critical issue of the tetraploid lines, which also appeared in the RP2 generation. Partial fertility and complete sterility segregated into the plants of the RP2-25, RP2-38, and RP2-80 lines (Table 1 and Supplementary Table 6). The relationships between these fertilities and HS loci were not clear in this study, although tetraploidy could mitigate sterility in a certain genetic background (Supplementary Table 6). The seed sizes of RP238 and RP2-80 lines were respectively 1.3 to 1.4 times larger than those of the parental lines and were inherited by the next generation (Table 1). Plant heights, flag-leaf lengths, flag-leaf widths, and ligule lengths of plants grown from the seeds of RP2-25, RP2-38, and RP2-80 were superior to the parental traits (Table 1). This typical biomass enlargement may have been due to tetraploidization; alternatively, heterosis may have occurred, as the genomes of these strains were heterozygous. In the sat-gla diploid $F_{1}$ hybrid, however, the values of these traits were often intermediate between those of the parents, and the tetraploid vigor was thus unlikely the result of heterosis (Table 1). Even if heterosis was a factor-given that these tetraploid plants retained heterozygous genomes-the maintenance of heterotic traits in the progeny would be difficult.

In a tetraploid plant with two different alleles at a locus, 10 generations are theoretically required to reduce the proportion of heterozygotes to less than one-quarter of a population; in a diploid plant, this percentage is achieved by the third generation. This characteristic implies that the number of generations during which recombination can take place in a heterozygous tetraploid is much larger compared with a diploid (Pecinka et al., 2011). Tetraploid hybrid plants therefore have the potential to create highly variable allelic combinations by repeated recombination during meiosis.

\section{DATA AVAILABILITY STATEMENT}

The datasets presented in this study can be found in online repositories. The names of the repository/repositories and 
accession number(s) can be found in the article/Supplementary Material.

\section{AUTHOR CONTRIBUTIONS}

DK and YKi conceived and planned the work. DK, IM, YKa, and YS-K performed the experiments and analyzed the data. YO directed the anther culture procedure. HY arranged the materials. DK, TY, and KN performed immunochemical staining. YH assisted with the ploidy analysis. YKo assisted with the data analyses. IT supported the mitotic observations. DK and YKi wrote and improved the manuscript. YKi supervised DK's Ph.D. study. All authors contributed to the article and approved the submitted version.

\section{FUNDING}

This work was supported by grants from JSPS KAKENHI (no. 19H00937 to YKi) and the Hokkaido University Research and Education Center for Robust Agriculture, Forestry and Fisheries Industry (to YKi). This work was partly supported by the Joint Usage/Research Center, Institute of Plant Science and Resources, Okayama University.

\section{ACKNOWLEDGMENTS}

We are grateful for the help of Dr. S. Ishiguro, Mr. Y. Ota, and Ms. R. Iwashiro (Laboratory of Plant Breeding, Hokkaido University) in conducting this study. We thank Dr. N. Ohmido (Graduate School of Human Development and Environment,

\section{REFERENCES}

Chu, C. C. (1978). "The N6 medium and its applications to anther culture of cereal crops," in Proceedings of Symposium on Plant Tissue Culture, Beijing, 43-50.

De Storme, N., and Geelen, D. (2013). Sexual polyploidization in plants-cytological mechanisms and molecular regulation. New Phytol. 198, 670-684. doi: 10.1111/ nph.12184

Doi, K., Taguchi, H., and Yoshimura, A. (1999). RFLP mapping of S20 and S21 for F1 pollen semi-sterility found in backcross progeny of Oryza sativa and O. glaberrima. Rice Genet. Newsl. 16, 65-68.

Doi, K., Taguchi, K., and Yoshimura, A. (1998). A new locus affecting high F1 pollen sterility found in backcross progenies of Japonica rice and African rice. Rice Genet. Newsl. 15, 146-147.

Garavito, A., Guyot, R., Lozano, J., Gavory, F., Samain, S., Panaud, O., et al. (2010). A genetic model for the female sterility barrier between Asian and African cultivated rice species. Genetics 185, 1425-1440. doi: 10.1534/genetics. 110.116772

Germana, M. A. (2011). Anther culture for haploid and doubled haploid production. Plant Cell Tissue Organ. Cult. 104, 283-300. doi: 10.1007/s11240010-9852-z

Gopalakrishnan, R., Nayar, N. M., and Sampath, S. (1964). Cytogenetical studies of two amphidiploids in the genus Oryza. Euphytica 13, 57-64. doi: 10.1007/ BF00037519

Grewal, D., Manito, C., and Bartolome, V. (2011). Doubled haploids generated through anther culture from crosses of Elite Indica and Japonica cultivars and/or lines of rice: large-scale production, agronomic performance, and
Kobe University) for valuable technical advice. We also thank Edanz Group (www.edanzediting.com/ac) for editing the English text of a draft of this manuscript. This manuscript has been released as a pre-print at bioRxiv (Kuniyoshi et al., 2020).

\section{SUPPLEMENTARY MATERIAL}

The Supplementary Material for this article can be found online at: https://www.frontiersin.org/articles/10.3389/fpls.2020. 579305/full\#supplementary-material

Supplementary Figure 1 | Information of chromosomal locations (above) and primers (below) for the genotyped loci.

Supplementary Figure 2 | A genotyping profile of the 19 regenerated plants using 10-C2 located on centromere in the chromosome 10.

Supplementary Figure 3 | Seventeen regenerated plants obtained from AC of WK21/Nip F1.

Supplementary Table 1 | Numbers of the induced calli and regenerated plants by $\mathrm{AC}$ from the interspecific rice hybrids and their parents.

Supplementary Table 2 | Genotypes of the 19 regenerated plants from the calli of WK21/Nip F1 hybrids.

Supplementary Table 3 | Genetic zygosities of centromeric regions of the 12 chromosomes of 12 regenerated plants and detection of FDR and SDR.

Supplementary Table 4 | Numbers of PMCs indicating normal and anomaly in meiosis I (prophase I) and meiosis II (anaphase II to telophase II).

Supplementary Table $\mathbf{5}$ | Genotyping of the 12 HS loci in the 17 regenerated plants.

Supplementary Table 6 | Pollen fertility, seed set rate, and genotypes of HS loci for the self-pollinated progenies of the three fertile tetraploid lines, RP2-25, RP2-38, and RP2-80.

molecular characterization. Crop Sci. 51, 2544-2553. doi: 10.2135/cropsci2011. 04.0236

Gribaudo, I., Gambino, G., and Vallania, R. (2004). Somatic embryogenesis from grapevine anthers: the optimal developmental stage for collecting explants. Am. J. Enol. Vitic. 55, 427-430.

Guha, S., and Maheshwari, S. C. (1964). In vitro production of embryos from anthers of datura. Nature 204:497. doi: 10.1038/204497a0

Han, Z. Q., Geng, X. N., Du, K., Xu, C. P., Yao, P. Q., Bai, F. Y., et al. (2018). Analysis of genetic composition and transmitted parental heterozygosity of natural $2 \mathrm{n}$ gametes in Populus tomentosa based on SSR markers. Planta 247, 1407-1421. doi: 10.1007/s00425-018-2871-4

Hassawi, D. S., and Liang, G. H. (1990). Effect of cultivar, incubation-temperature, and stage of microspore development on anther culture in wheat and triticale. Plant Breed. 105, 332-336. doi: 10.1111/j.1439-0523.1990.tb01293.x

Hoekstra, S., Vanzijderveld, M. H., Louwerse, J. D., Heidekamp, F., and Vandermark, F. (1992). Anther and microspore culture of Hordeum-vulgare L Cv Igri. Plant Sci. 86, 89-96. doi: 10.1016/0168-9452(92)90182-L

Huang, N., Parco, A., Mew, T., Magpantay, G., McCouch, S., Guiderdoni, E., et al. (1997). RFLP mapping of isozymes, RAPD and QTLs for grain shape, brown planthopper resistance in a doubled haploid rice population. Mol. Breed. 3, 105-113. doi: 10.1023/A:1009683603862

Jauhar, P. P. (2007). Meiotic restitution in wheat polyhaploids (Amphihaploids): a potent evolutionary force. J. Hered. 98, 188-193. doi: 10.1093/jhered/esm011

Jones, M. P., Dingkuhn, M., Aluko, G. K., and Semon, M. (1997). Interspecific Oryza sativa L. X O. glaberrima Steud progenies in upland rice improvement. Euphytica 94, 237-246. doi: 10.1023/A:1002969932224 
Kanaoka, Y., Kuniyoshi, D., Inada, E., Koide, Y., Okamoto, Y., Yasui, H., et al. (2018). Anther culture in rice proportionally rescues microspores according to gametophytic gene effect and enhances genetic study of hybrid sterility. Plant Methods 14:102. doi: 10.1186/s13007-018-0370-Z

Kinoshita, A., Okamoto, Y., Ishimura, S., and Satake, T. (2000). Determination of optimum pollen development stage for inducing callus in anther culture of rice. Breed. Res. 2, 73-79.

Koide, Y., Ogino, A., Yoshikawa, T., Kitashima, Y., Saito, N., Kanaoka, Y., et al. (2018). Lineage-specific gene acquisition or loss is involved in interspecific hybrid sterility in rice. Proc. Natl. Acad. Sci. U.S.A. 115, E1955-E1962. doi: $10.1073 /$ pnas.1711656115

Koide, Y., Onishi, K., Nishimoto, D., Baruah, A. R., Kanazawa, A., and Sano, Y. (2008). Sex-independent transmission ratio distortion system responsible for reproductive barriers between Asian and African rice species. New Phytol. 179, 888-900. doi: 10.1111/j.1469-8137.2008.02490.x

Kuniyoshi, D., Masuda, I., Kanaoka, Y., Shimazaki-Kishi, Y., Okamoto, Y., Yasui, H., et al. (2020). Diploid male gametes circumvent hybrid sterility between Asian and African rice species. bioRxiv [Preprint]. doi: 10.1101/2020.05.27. 119180

Li, F., Liu, F. H., Morinaga, D., and Zhao, Z. (2011). A new gene for hybrid sterility from a cross between Oryza sativa and O. glaberrima. Plant Breed. 130, 165-171. doi: 10.1111/j.1439-0523.2010.01845.x

McCouch, S. R., Teytelman, L., Xu, Y., Lobos, K. B., Clare, K., Walton, M., et al. (2002). Development and mapping of 2240 new SSR markers for rice (Oryza sativa L.). DNA Res. 9, 199-207. doi: 10.1093/dnares/9.6.199

Miyashita, T., Araki, H., and Hoshino, Y. (2011). Ploidy distribution and DNA content variations of Lonicera caerulea (Caprifoliaceae) in Japan. J. Plant Res. 124, 1-9. doi: 10.1007/s10265-010-0341-6

Morinaga, T., and Kuriyama, H. (1957). Cytogenetical studies on Oryza sativa L. IV. The F1 hybrid of O. sativa L. and O. glaberrima Steud. Jpn. J. Breed. 7, 57-65. doi: 10.1270/jsbbs1951.7.57

Nagaki, K., Cheng, Z. K., Ouyang, S., Talbert, P. B., Kim, M., Jones, K. M., et al. (2004). Sequencing of a rice centromere uncovers active genes. Nat. Genet. 36, 138-145. doi: 10.1038/ng1289

Naik, N., Rout, P., Umakanta, N., Verma, R. L., Katara, J. L., Sahoo, K. K., et al. (2017). Development of doubled haploids from an elite Indica rice hybrid (BS6444G) using anther culture. Plant Cell Tissue Organ. Cult. 128, 679-689. doi: 10.1007/s11240-016-1163-6

Niizeki, H., and Oono, K. (1968). Induction of haploid rice plant from anther culture. Proc. Jpn. Acad. 44, 554-557. doi: 10.2183/pjab1945.44.554

Oka, H. I. (1957). Genic analysis for the sterility of hybrids between distantly related varieties of cultivated rice. J. Genet. 55, 397-409. doi: 10.1007/bf02984059

Oka, H. I. (1968). Preferential pairing of chromosomes in a tetraploid hybrid between Oryza glaberrima and O. sativa. Can. J. Genet. Cytol. 10, 527-535. doi: 10.1139/g68-071

Ouyang, Y. D., and Zhang, Q. F. (2013). Understanding reproductive isolation based on the rice model. Annu. Rev. Plant Biol. 64, 111-135. doi: 10.1146/ annurev-arplant-050312-120205

Pecinka, A., Fang, W., Rehmsmeier, M., Levy, A. A., and Scheid, O. M. (2011). Polyploidization increases meiotic recombination frequency in Arabidopsis. BMC Biol. 9:24. doi: 10.1186/1741-7007-9-24

Pinson, S. R. M., and Rutger, J. N. (1993). Heterozygous diploid plants regenerated from anther culture of F1 rice plants. In Vitro Cell. Dev. Biol. Plant 29, 174-179. doi: $10.1007 / \mathrm{bf} 02632031$

Ren, G., Xu, P., Deng, X., Zhou, J., Hu, F., Li, J., et al. (2006). A new gamete eliminator from Oryza glaberrima. Rice Genet. Newsl. 22, 43-44.

Rout, P., Naik, N., Ngangkham, U., Verma, R. L., Katara, J. L., Singh, O. N., et al. (2016). Doubled Haploids generated through anther culture from an elite long duration rice hybrid, CRHR32: method optimization and molecular characterization. Plant Biotechnol. 33, 177-186. doi: 10.5511/ plantbiotechnology.16.0719a

Sano, Y. (1983). Genetic studies of speciation in cultivated Rice . 3. A new gene controlling sterility in F1 hybrids of 2 cultivated rice species: its association with photoperiod sensitivity. J. Hered. 74, 435-439. doi: 10.1093/oxfordjournals. jhered.a109832

Sano, Y. (1990). The genic nature of gamete eliminator in rice. Genetics 125, $183-191$.

Sano, Y., Chu, Y. E., and Oka, H. I. (1979). Genetic-studies of speciation in cultivated rice . 1. Genic analysis for the F1 sterility between Oryza sativa L and O. glaberrima Steud. Jpn. J. Genet. 54, 121-132.

Taguchi, K., Doi, K., and Yoshimura, A. (1999). RFLP mapping of S19, a gene for F1 pollen semi-sterility found in backcross progeny of Oryza sativa and O. glaberrima. Rice Genet. Newsl. 16, 70-71.

Telmer, C. A., Simmonds, D. H., and Newcomb, W. (1992). Determination of developmental stage to obtain high-frequencies of embryogenic microspores in Brassica-Napus. Physiol. Plant 84, 417-424. doi: 10.1111/j.1399-3054.1992. tb04685.x

Woo, S. C., Mok, T., and Huang, J. Y. (1978). Anther culture of Oryza-Sativa-L and Oryza-Perennis Moench Hybrids. Bot. Bull. Acad. Sin. 19, 171-178.

Xie, Y. Y., Tang, J. T., Xie, X. R., Li, X. J., Huang, J. L., Fei, Y., et al. (2019). An asymmetric allelic interaction drives allele transmission bias in interspecific rice hybrids. Nat. Commun. 10:2501.

Xie, Y. Y., Xu, P., Huang, J. L., Ma, S. J., Xie, X. R., Tao, D. Y., et al. (2017). Interspecific hybrid sterility in rice is mediated by OgTPR1 at the S1 locus encoding a peptidase-like protein. Mol. Plant 10, 1137-1140. doi: 10.1016/j. molp.2017.05.005

Xu, P., Zhou, J. W., Li, J., Hu, F. Y., Deng, X. N., Feng, S. F., et al. (2014). Mapping three new interspecific hybrid sterile loci between Oryza sativa and O. glaberrima. Breed. Sci. 63, 476-482. doi: 10.1270/jsbbs.63.476

Yan, G. J., Liu, H., Wang, H. B., Lu, Z. Y., Wang, Y. X., Mullan, D., et al. (2017). Accelerated generation of selfed pure line plants for gene identification and crop breeding. Front. Plant Sci. 8:1786. doi: 10.3389/fpls.2017.01786

Yang, J. Y., Zhao, X. B., Cheng, K., Du, H. Y., Ouyang, Y. D., Chen, J. J., et al. (2012). A killer-protector system regulates both hybrid sterility and segregation distortion in rice. Science 337, 1336-1340. doi: 10.1126/science.1223702

Yu, X., Zhao, Z., Zheng, X., Zhou, J., Kong, W., Wang, P., et al. (2018). A selfish genetic element confers non-Mendelian inheritance in rice. Science 360, 1130-1132. doi: 10.1126/science.aar4279

Zhang, Z., Xu, P., Hu, F., Zhou, J., Li, J., Deng, X., et al. (2006). A new sterile gene from Oryza glaberrima on chromosome 3. Rice Genet. Newsl. 22, 26-28.

Zhu, Y. F., Yu, Y. M., Cheng, K., Ouyang, Y. D., Wang, J., Gong, L., et al. (2017). Processes underlying a reproductive barrier in Indica-Japonica rice hybrids revealed by transcriptome analysis. Plant Physiol. 174, 1683-1696. doi: 10.1104/ pp.17.00093

Conflict of Interest: The authors declare that the research was conducted in the absence of any commercial or financial relationships that could be construed as a potential conflict of interest.

Copyright (c) 2020 Kuniyoshi, Masuda, Kanaoka, Shimazaki-Kishi, Okamoto, Yasui, Yamamoto, Nagaki, Hoshino, Koide, Takamure and Kishima. This is an open-access article distributed under the terms of the Creative Commons Attribution License (CC BY). The use, distribution or reproduction in other forums is permitted, provided the original author(s) and the copyright owner(s) are credited and that the original publication in this journal is cited, in accordance with accepted academic practice. No use, distribution or reproduction is permitted which does not comply with these terms. 